\title{
Farklı Heterotik Gruplar Arasındaki Tekli ve Üçlü Melez Atdişi Mısır (Zea mays indentata Sturt.) Populasyonlarında Verim ve Bazı Verim Komponentlerinin Değerlendirilmesi
}

\author{
Öner YEŞiLKAYA ${ }^{1}$ Soner BAŞARAN¹ $\quad$ Mehmet ÖZÜSTÜN ${ }^{1}$ *Muzaffer TOSUN² \\ ${ }^{1}$ Polen Tohumculuk ve Tarım Ürünleri San. ve Tic. Ltd. Şirketi, Manisa \\ ${ }^{2}$ Ege Üniversitesi, Ziraat Fakültesi, Tarla Bitkileri Bölümü, İzmir \\ *Sorumlu yazar e-posta (Corresponding author; e-mail): muzaffer.tosun@ege.edu.tr
}

\begin{abstract}
Öz
Bu araştırmada hibrit mısır çeşidi geliştirilebilmesi için dört hat ve üç testerin LinexTester metoduna uygun melezlemeleri yapılmış ve denemeler Polen Tohumculuk ve Tarım Ürünleri San. ve Tic. Ltd. Şti'nin Adana, Incirlik Dedepınarı mevkiindeki deneme istasyonunda gerçekleştirilmiştir. 2009 yılında line $x$ tester melezlemeleri yapılarak $F_{1}$ tohumlukları elde edilmiştir. $F_{1}$ tohumlukları 2010 yılında Tesadüf Blokları Deneme Desenine göre dört tekrarlı ekilmiş ve verim ve diğer verim komponentleri için ebeveynlere ait genel kombinasyon gücü, özel kombinasyon gücü tahminlemeleri yapılmıştır. Bunun yanında verim ve bitki boyu için heterobeltiosis yüzdeleri de saptanmıştır. Çalışmamız sonucunda, R4062xR4046 hattının verim, koçanda sıra sayısı, sırada tane sayısı özelliklerini döllerine yüksek oranda aktarabilme yeteneğine sahip olduğu anlaşılmaktadır. Aynı zamanda bu R4062 ve R4046 hatlarıın çekirdek genlerinin büyük ölçüde birbirine benzediği de moleküler analizlerle ortaya konmuştur. Testerler içerisinde FR697'nin ıslah çalışmalarında iyi bir tester olarak kullanılabileceği görülmektedir. Melezler içerisinde ise R4062xFR697 tek melezinin tane verimi açısından, R4046xGS3507 melez kombinasyonunun ise tane verimi, koçan bağlama yüksekliği ve sırada tane sayısı açısından ümitvar hibrit kombinasyonları oluşturdukları ve dendogram analizlerinde de bu genotiplerin birbirlerinden genetiksel olarak uzak akraba oldukları görülmüştür. Bu kombinasyonların diğer agronomik ve kalite özellikleri de incelenerek hibrit çeşit olarak ele alınabilecekleri sonucuna varılmıştır.
\end{abstract}

Anahtar Kelimeler: Hibrit mısır, heterosis, genel ve özel kombinasyon yeteneği

\section{The Evaluation of Yield and Some Yield Components of Single and Three - Way Cross Dent Corn (Zea mays indentata Sturt.) Populations in Between Different Heterotic Groups}

\begin{abstract}
In this study, for the development of hybrid varieties of maize, four lines and three tester have been crossed according to the method of Linex Tester, and this trial has been conducted at the trial station of Polen Tohumculuk Ltd.Sti. located in Incirlik, Dedepinari of Adana Province. In 2009, the $F_{1}$ seed was obtained from line $x$ tester cross. $F_{1}$ seeds have been planted in 2010 according to the randomized complete block design with four repeated and for the yield and yield components, general combining ability, specific combining ability of parents have been predicted. In addition, the percentage of heterobeltiosis for the yield and plant height was determined. It was found as result that, the line of R4062xR4046 has capable transferring of its yield, kernel row number, number of kernels on the row characters to offspring's with very high rates, so that it can be used for this purpose. Also the core genes of R4062 and R4046 were revealed greatly resemble each other in the molecular analysis. Among the testers, the FR697 can be used as a good tester in the breeding programs. Among the hybrid crosses, R4062xFR697 is superior for grain yield and the hybrid combination of R4046xGS3507 in terms of grain yield, ear placement and number of kernels on the row was formed promising hybrid combinations. Dendogram analysis of these genotypes shows that these genotypes are genetically distant relatives, is noteworthy. As a result of examination of these combinations' other agronomic and quality features, it is concluded that these genotypes can be handled as hybrid variety.
\end{abstract}

Keywords: Hybrid corn, heterosis, general and specific combining ability 


\section{Giriş}

nsan ve hayvan beslenmesinde çok önemli yer alan mısır (Zea mays indentata Sturt.) dünyada buğday ve çeltiğin ardından, ülkemizde ise buğday ve arpadan sonra üçüncü sırayı alan tahıl bitkisidir. 2011 yılı Türkiye İstatistik Kurumu istatistiklerine göre ülkemizin mısır ekim alanı (silaj ve tane) 9.959.376 da olup, tane mısır üretimi 4.200 .000 ton ve dekara ortalama verimi $713 \mathrm{~kg}$ olarak belirlenmiştir. Türkiye'de mısır tarımı, ekim alanı ve üretimi bakımından sırasıyla en fazla Akdeniz, Marmara, Ege ve Güneydoğu Anadolu bölgelerinde yapılmaktadır (TÜİK 2011). Ayrıca Ege, Akdeniz ve Güneydoğu Anadolu bölgelerinin sulanabilir tarım alanlarında, buğday ve arpa hasadından sonra ikinci ürün mısır tarımına geçilmesiyle mısır üretiminde önemli artışlar sağlanabilecektir.

Ülkemizde üretilen mısırın tamamına yakını yurt içinde tüketilmektedir. Entansif hayvancılığın gelişmesi ile paralel gelişme gösteren yem sanayi mısıra duyulan talebi artırmış ve hibrid tohumluk kullanımının yaygınlaşması sonucu üretimde artışlar kaydedilmiştir. Mısırın çok sayıda kullanım alanı olup, bitkinin her parçası ayrı bir ekonomik değere sahiptir. Günümüzde mısırın doğrudan veya dolaylı olarak üretimine katıldığı 4.000 civarında farklı ürün mevcuttur. Mısırın başlıca kullanım alanları; taze olarak tüketim (haşlama ve közleme), konserve, mısır unu, nişasta, cips, çerez, daneleri ve yeşil aksamı hayvan yemi olarak, yağ, tatlandırıcı, şekerleme, çiklet, çikolata ürünleri, bebek mamaları, salata sosları, alkol, yüksek früktozlu mısır şurubu, diş macunu, etanol (benzine katkı maddesi olarak) üretiminde ve otomotiv sanayi, temizlik malzemeleri, tekstil ve kozmetik sanayi olarak sayılabilir (Özcan 2009). Mısırın çok geniş bir kullanım alanının bulunması önemini gittikçe artırmaktadır. Mısır zengin bir nişasta kaynağı olup, içeriğinde ortalama olarak \%75 nişasta, \%9 protein, \%9 lif, \%4 yağ, \%2 şeker, \%2 kül bulunmaktadır.

Bitki ıslahında melez çeşit geliştirme açısından önem taşıyan heterosis, ticari anlamda birçok türde uygulama alanı bulmuştur. Melez çeşidin performans bakımından kendilenmiş anaçlardan üstün olmasını gösteren heterosis, melezi oluşturan anaçların kombinasyon yeteneği ile de önemli düzeyde ilişkilidir. Heterosisin ortaya çıkışı bitki türlerinde çok yaygın olmakla birlikte, miktar veya seviye olarak türden türe oldukça farklılıklar göstermektedir. Genel olarak, heterosis yabancı döllenen bitki türlerinde kendine döllenenlere göre daha yüksek oranda ortaya çıkmaktadır. Günümüzde özellikle ayçiçeği ve mısır ıslahında heterosis yaygın olarak uygulama alanı bulmaktadır. Genel ve özel kombinasyon yeteneği yüksek olan hatlar arasında yapılan melezleme sonrasında melez gücü yüksek olan hatlar belirlenmeye çalışılır. Melez gücü, kendilenmiş hatlar arasındaki melezlerin anaç ortalama değerine (heterosis) veya üstün anaç değerine (heterobeltiosis) üstünlük göstermesi şeklinde tanımlanmaktadır (Cengiz 2011).

Mısır ıslah programlarında ticari üretim için yüksek verimli melezlerin geliştirilmesi en başta gelen amaçlardandır (Stangland ve ark. 1983). Mısır ıslahının başlarında ebeveynler arası kombinasyon yeteneklerini belirlemek amacıyla genotipler arasında olası tüm melezler yapılmakta iken Davis (1927) tarafından daha kolay bir yöntem olan test melezi (yoklama melezi) yöntemi önerilmiştir. Belirli sayıdaki homozigot hat arasında yapılan melezlemelerle oluşturulan populasyonlarda, genetik varyans komponentlerinin hesaplanması ve uyum yetenekleri etkilerinin belirlenmesi amacıyla çeşitli metotlar geliştirilmiştir (Hayman 1954; Griffing 1956; Kempthorne 1957). Kempthorne (1957) tarafından önerilen ve yoklama melezinin (top cross) değişik bir şekli olan Line $\mathrm{x}$ Tester analizi hem kendine hem de yabancı döllenen bitkilerde yaygın olarak kullanılan yöntemlerden birisidir (Singh and Chaudhary 1977). Line x Tester analiz yöntemi, Islahçılara melezleme ıslahındaki anaçların seçiminde seleksiyonun sistematik bir yaklaşımla yapılmasını ve istenilen özellikler için üstün anaçlar arasında melezleme yapma olanağını sağlamaktadır. Aynı zamanda, farklı genetik parametrelerin tahminlenmesine olanak sağladığı için ıslahçıların kullanabileceği en etkili ıslah yöntemini seçmesine de yardımcı olmaktadır (Bozbek, 2006).

$\mathrm{Bu}$ araştırma ile farklı heterotik yapıya sahip 7 ebeveyn (saf hat) ile bunların melezlenmesi ile elde edilen 12 adet tek melez kombinasyonlarında verim ve verim komponentleri açısından kendi içlerinde varyasyon olup olmadığı araştırılmıştır. $\mathrm{F}_{1}$ 'lerden elde edilen veriler kullanılarak mutlak ve oransal heterobeltiosis değerleri ile anaçlar ve $F_{1}$ 'ler için uyum yetenekleri belirlenerek, uygun melez kombinasyonların belirlenmesinin yanında, mısır ıslahçılarına anaç seçiminde ve 
Islah edilmesi planlanacak uygun melez tipinin saptanmasında yardımcı olacak bazı bilgilerin sağlanması amaçlanmaktadır.

\section{Materyal ve Yöntem}

Denemeler Polen Tohumculuk ve Tarım Ürünleri San. ve Tic. Ltd. Şti'nin Adana, İncirlik Dedepınarı mevkiindeki deneme istasyonunda gerçekleştirilmiştir. Hat ve tester olarak kullanılan ebeveynler firmanın bünyesinde bulunan homozigot bireylerden oluşmaktadır. 2009 yılında line $x$ tester melezlemeleri yapılarak $F_{1}$ tohumlukları elde edilmiştir. $F_{1}$ tohumlukları 20.03.2010 tarihinde ekilmiş ve 30.08.2010 tarihinde de hasat işlemi gerçekleştirilmiştir. Tesadüf Blokları Deneme Desenine göre dört tekrarlı kurulan denemenin her bir parseli dört adet sıradan oluşturulmuştur. Parsel içerisinde sıra arası 0.7 metre ve sıra uzunluğu $5 \mathrm{~m}$ olup, parsel alanı $10.5 \mathrm{~m}^{2} \mathrm{dir}$. Her bir tekerrür arasında ise 1'er metre boşluk bırakılmıştır.

Deneme alanı kumlu ve tınlı bir toprak yapısına sahiptir. Yabancı ot ile mücadele edebilmek amacıyla vegetasyon süresi boyunca iki kez herbisit uygulaması yapılan çalışmada, herhangi bir insektisit kullanılmamıştır. Dekara $25 \mathrm{~kg}$ saf $\mathrm{N}, 10 \mathrm{~kg}$ $\mathrm{P}_{2} \mathrm{O}_{5}$ ve $12 \mathrm{~kg} \mathrm{~K}$ hesabıyla, parsellere fosfor ve potasyum ekimle birlikte, azot ise adı geçen miktarın yarısı elle serpme olarak ekimle birlikte ve kalan yarısı da bitkilerin ortalama $40 \mathrm{~cm}$ boylandığı evrede amonyum nitrat formunda $\left(\mathrm{NH}_{4} \mathrm{NO}_{3}\right)$ verilmiştir. Genç mısır bitkileri toprak üzerine çıktıktan 10-15 gün sonra ilk ara çapalama işlemi gerçekleştirilmiş ve bu işlem iki defa daha uygulanmıştır. İkinci gübre uygulamasıyla beraber karık çekme ve boğaz doldurma işlemleri yapılmış olup, denemede toprağın nem durumuna bakılarak altı kez sulama işlemi gerçekleştirilmiştir.

Çalışmada Polen Tohumculuk'a ait kendilenmiş ebeveynler hat ve tester olarak kullanılmıştır. $\mathrm{Bu}$ hatlar Çizelge 1'de sunulmuştur. Kendilenmiş hatlardan R4046 ve
R4062 için resiproklu melezleme gerçekleştirilmiş ve bu melezler değiştirilmiş saf hat olarak kullanılmıştır. Hatlar çoklu dizi şeklinde testerlerle 2009 yılında melezlenmiş ve elde edilen $F_{1}$ kademesindeki hibrit kombinasyonlar aşağıda sunulmuştur.

Elde edilen 12 hibrit genotip 20.03.2010 tarihinde Polen Tohumculuk şirketinin Adana Araştırma İstasyonunda ebeveynleri ile birlikte tesadüf blokları deneme desenine uygun olacak şekilde dört tekrarlı yetiştirilmiş ve gözlemlenmiştir. Daha sonra veriler çoklu dizi (line $x$ tester) analiz yöntemi kullanılarak ebeveynlerin genel ve özel kombinasyon güçleri ve gen etkileri Singh ve Chaudhary (1977) tarafından açıklandığı şekilde hesaplanmış, analize ilişkin hesaplamalar MS OFFICE EXCEL 2003 programı ile yapılmıştır.

Tane Verimi (kg/parsel): Denemenin ekim planına göre her parselde bulunması gereken bitki sayısı ve her parseldeki mevcut bitki sayısı belirlenmiş olup, orta iki sıranın hasatı yapılarak parsel verim değerleri elde edilmiştir.

Koçanda Sıra Sayısı (adet): Her parselden tesadüfen alınan 10 koçan örneğinde, koçan üzerindeki mevcut sıra sayısı belirlenmiştir.

Sırada Tane Sayısı (adet/koçan): Her parselden tesadüfen alınan 10 koçanın üzerinde koçanın boyuna yer alan sıralardaki tane sayısı belirlenmiştir.

Parselde Koçan Sayısı (adet): Her parselde, ortadaki iki sırada yer alan ve tüm bitkilerden elde edilen koçan adetleri belirlenmiş ve adet cinsinden saptanmıştır.

Bitki Boyu (cm): Her parselde, ortadaki iki sırada yer alan ve tesadüfen seçilen 10 bitkide, toprak seviyesinden tepe püskülünün en uç noktasına kadar olan mesafe $\mathrm{cm}$ cinsinden ölçülerek bulunmuştur.

Koçan Bağlama Yüksekliği $(\mathrm{cm})$ : Her parselde bitki boyunun ölçüldüğü 10 bitkide, toprak seviyesinden ilk koçanın çıktığı boğum arasındaki mesafe $\mathrm{cm}$ cinsinden ölçülmüştür.

Çizelge 1. Çalışmada kullanılan hat ve testerler ile oluşturulan hibritler

Table 1. Hybrids of lines and testers used in experiments

\begin{tabular}{llll}
\hline & & \multicolumn{1}{c}{ Testerler } & \\
\hline \multicolumn{1}{c}{ Hatlar } & \multicolumn{1}{c}{ FR697 } & \multicolumn{1}{c}{ GS3507 } & \multicolumn{1}{c}{ GS3515 } \\
\hline R4046 & R4046 x FR697 & R4046 x GS3507 & R4046 x GS3515 \\
R4046 x 4062 & (R4046xR4062)x FR697 & (R4046xR4062)x GS3507 & (R4046 x R4062) x GS3515 \\
R4062 & R4062 x FR697 & R4062 x GS3507 & R4062 x GS3515 \\
R4062 x R4046 & (R4062xR4046)x FR697 & (R4062xR4046)x GS3507 & (R4062 x R4046) x GS3515 \\
\hline
\end{tabular}




\section{Bulgular ve Tartışma}

\section{Tane Verimi}

4 hat ve 3 testerden oluşan ve toplam 12 kombinasyona ait olan tane verimine ilişkin değerlerin varyans analizi sonucunda genotip, ebeveynler, ebeveyn ve melezler, melezler, hat ve testerler ile hat $\mathrm{x}$ tester interaksiyonunun istatistiksel düzeyde önemli olduğu anlaşılmaktadır (Çizelge 1 ve 2). Bu durum line tester genetik analizinin yapılmasının olanaklı olduğunu ortaya koymaktadır.

Tane verimi özelliği bakımından genel ve özel kombinasayon gücü varyans tahminleri eklemeli ve dominant varyans komponentleri ile bunların arasındaki oransal ilişkiler incelendiğinde, tane verimi özelliği için özel kombinasyon gücü varyansının GKG varyansından büyük oldugu gözlenmektedir (Çizelge 3). Aynı zamanda GKG varyansı negatif değer almış olup bu populasyonda eklemeli etkilerin önemli olmadığını, buna karşın dominant etkilerin ön planda bulunduğunu ortaya koymaktadır. Çünkü GKG / ÖKG oranına bakıldığında rakamsal olarak "1" den oldukça küçük olduğu ve tane veriminin oluşumunda eklemeli olmayan gen etkilerinin yüksek oranda bulunduğunu ortaya koymaktadır. Mathur ve Bhatnagar (1995) ve Sfakinakis ve ark. (1996)'da mısırda özellikle verim yönünden yani hibrit ticari çeşit bakımından, dominant gen etkilerinin daha önemli olduğunu vurgulamışlardır.
Ayrıca (H/D)1/2 oranının 1'den küçük bulunması eklemeli olmayan gen etkileri içerisinde dominant etkilerin yanında epistatik etkileşimlerin de yüksek olduğunu, bunun da heterotik etkilerin göründüğü çizelge incelendiğinde (Çizelge 5) heterobeltiosis değerlerinin oldukça yüksek olduğu görülmektedir. Elde edilen heterobeltiosis değerleri çalışmaya konu olan tüm melezler için pozitif olduğu ve yüksek oranlarda elde edildiği Çizelge 5'den anlaşılmaktadır. Hibritlere ait verim ortalamaları 10.20 ile 13.25 kg/parsel arasında değişim göstermiştir.

Tane verimi özelliği ile ilişkili GKG değerleri incelendiğinde (Çizelge 4) hatlar içerisinde R4046 x R4062 negatif önemli olurken, bunun resiproku olan R4062 x R4046 hattının pozitif ve önemli olduğu, buna karşın testerlerin hiç birinde önemlilik bulunmadığı anlaşılmaktadır. Bu durum tane verimi açısından R4062 x R4046 hattının eklemeli etkili genlere sahip olduğunu göstermektedir. Kombinasyon ıslahında seleksiyonun başarılı olması populasyondak mevcut eklemeli gen varyansına bağlı bulunduğundan ve GKG değerleri de eklemeli varyansa dayandığından (Falconer 1981) GKG değerleri yüksek olan ebeveynlerin melezlerinde seleksiyon yoluyla eklemeli varyanstan yararlanılabilmektedir. Yapılacak ıslah amacına göre GKG değerleri yüksek olan ebeveynlerin diğer gözlemleri de dikkate alınarak ümitvar olanlar bu amaçla kullanılabilecektir.

Çizelge 2. Ebeveyn ve melezler için tane verimine ait ön varyans analiz tablosu

Table 2. Primary variance analysis for parents and hybrids

\begin{tabular}{ccccc}
\hline Kaynak & S.D. & K.T. & K.O. & F \\
\hline Tekerrür & 3 & 2056488.16 & 685496.05 & 1.17 \\
Genotip & 18 & 862013703 & $47889650^{* *}$ & 81.67 \\
Ebeveynler & 6 & 91332650 & $15222108^{* *}$ & 25.96 \\
Melezler & 11 & 24438400 & $2221672.70^{* *}$ & 3.79 \\
Ebeveyn ve Melezler & 1 & $5896 \times 10^{6 * *}$ & $5896 \times 10^{* *}$ & 10056.92 \\
Hata & 54 & 31662686.8 & 586346.05 & \\
\hline
\end{tabular}

Çizelge 3. Parsel verimi için çoklu dizi varyans analiz sonuçları

Table 3. Sum of Squares of line $x$ tester analysis for yield

\begin{tabular}{ccccc}
\hline Kaynak & S.D. & K.T. & K.O. & F \\
\hline Hatlar & 3 & 4673883.33 & $1557961.11^{* *}$ & 2.65 \\
Testerler & 2 & 5060487.50 & $2530243.75^{* *}$ & 4.31 \\
Hat x tester & 6 & 14704029.17 & $2450671.53^{* *}$ & 4.18 \\
Hata & 54 & 31662686.84 & 586346.053 & \\
\hline
\end{tabular}

Çizelge 4. Parsel verimi için genel kombiansyon gücü (GKG) ve özel kombinasyon gücü (ÖKG)varyansları ve birbirlerine oranları

Table 4. General Combination Ability (GKG) and Special Combination Ability (ÖKG) variances and ratios

\begin{tabular}{ccccccc}
\hline Karakterler & GKG & ÖKG & GKG/ÖKG & D & H & $(\mathrm{H} / \mathrm{D})^{1 / 2}$ \\
\hline Parsel verimi & -14817.57 & 466081.37 & -0.02 & -29635.14 & 466081.37 & 3.97 \\
\hline
\end{tabular}


Yeşilkaya ve ark. "Farklı Heterotik Gruplar Arasındaki Tekli ve Üçlü Melez Atdişi Mısır (Zea mays indentata Sturt.) Populasyonlarında Verim ve Bazı Verim Komponentlerinin Değerlendirilmesi"

Çizelge 5. İncelenen karakterlere ait deneme gözlem ortalamaları ve tane verimine ilişkin heterobeltiosis yüzdeleri

Table 5. Observation averages of characters and heterobeltiosis percents of grain yield

\begin{tabular}{lcccccccc}
\hline \multicolumn{1}{c}{ Genotipler } & $\begin{array}{c}\text { Koç. } \\
\text { sayısı }\end{array}$ & $\begin{array}{c}\text { Bitki } \\
\text { boyu } \\
(\mathrm{cm})\end{array}$ & $\begin{array}{c}\text { Koçan } \\
\text { yük } \\
(\mathrm{cm})\end{array}$ & $\begin{array}{c}\text { Koçanda } \\
\text { sıra } \\
\text { sayıs }\end{array}$ & $\begin{array}{c}\text { Sirada } \\
\text { tane } \\
\text { sayıs }\end{array}$ & $\begin{array}{c}\text { Parsel } \\
\text { verimi } \\
\mathrm{kg} / \mathrm{p}\end{array}$ & $\begin{array}{c}\text { Verim için } \\
\text { Heterobel } \\
(\%)\end{array}$ & $\begin{array}{c}\text { Verim için } \\
\text { GKG/ÖKG }\end{array}$ \\
\hline (R4046xR4062)xFR697 & 47 & 319 & 125 & 16 & 47 & 11.19 & 292.72 & -427.290 \\
(R4046xR4062)xGS3507 & 50 & 284 & 115 & 15 & 45 & 10.86 & 281.31 & 365.210 \\
(R4046xR4062)xGS3515 & 53 & 313 & 116 & 16 & 45 & 11.22 & 293.95 & 62.080 \\
(R4062xR4046)xFR697 & 53 & 309 & 126 & 15 & 49 & 11.11 & 47.79 & -176.460 \\
(R4062xR4046)xGS3507 & 51 & 317 & 119 & 16 & 46 & 10.20 & 35.75 & -288.960 \\
(R4062xR4046)xGS3515 & 53 & 295 & 117 & 15 & 45 & 11.30 & 86.89 & 465.420 \\
R4046xFR697 & 54 & 290 & 109 & 16 & 44 & 11.37 & 61.27 & -534.790 \\
R4046xGS3507 & 53 & 303 & 113 & 16 & 47 & 11.88 & 68.50 & $767.71^{* *}$ \\
R4046xGS3515 & 50 & 289 & 118 & 16 & 47 & 11.22 & 117.22 & -232.92 \\
R4062xFR697 & 55 & 309 & 116 & 15 & 48 & 13.25 & 170.60 & $1138.54^{* *}$ \\
4062xGS3507 & 51 & 293 & 111 & 15 & 45 & 10.47 & 113.93 & $-843.96^{* *}$ \\
R4062xGS3515 & 42 & 290 & 116 & 15 & 46 & 11.36 & 119.93 & -294.58 \\
1 (R4046xR4062) & 51 & 227 & 81 & 17 & 26 & 2.85 & & $-446.66^{* *}$ \\
2 (R4062xR4046) & 49 & 243 & 95 & 17 & 32 & 7.52 & & $380.83^{* *}$ \\
3 R4046 & 47 & 245 & 85 & 16 & 34 & 7.05 & & -113.33 \\
4 R4062 & 56 & 225 & 77 & 15 & 32 & 4.90 & & 179.16 \\
5 FR697 & 55 & 227 & 77 & 11 & 28 & 3.42 & & 415.62 \\
6 GS3507 & 50 & 195 & 76 & 10 & 30 & 2.68 & & -376.88 \\
7 GS3515 & 47 & 219 & 81 & 12 & 32 & 5.17 & & -38.75 \\
\hline
\end{tabular}

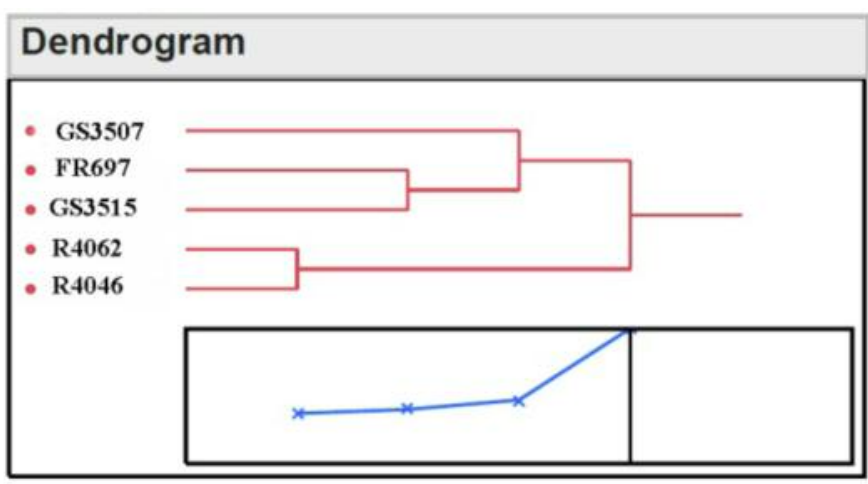

Şekil 1. Hat ve Testerler arasında SNP markörlerine dayalı akrabalık ilişkileri

Figure 1. Dendogram analysis of lines and tester's SNP markers

Çalışmamızda melez generasyonu hibrit ıslahında kullanılacağından çalışmadaki hatlar içerisinde R4062 x R4046 hattının diğer testerlerle oluşturduğu melez değerlerinin birbirine yakın olduğu görülmektedir.

Melez generasyonun ÖKG değerleri incelendiğinde (Çizelge 5), melez populasyonlar içerisinde R4062 x FR697 melezinin pozitif ve en yüksek ÖKG değerine sahip olduğu, bunu R4046 x GS3507 nin izlediği görülmektedir. Bu iki melez kombinasyonun hibrit ıslahında tane verimi açısından ümitvar aday kombinasyonlar olduğu, bu melezlerin diğer agronomik özellikleri de dikkate alınarak, ilgili ebeveynlerin hibrit ıslahında kullanılabilecekleri anlaşılmaktadır.

\section{Hat ve Testerlerin Akrabalık İlişkileri}

Çalışmada ele alınan hat ve testerlerin akrabalık ilişkileri BioDiagnostics (USA) şirketinde SNP markörlerine dayalı genotipleme yapılarak bu hat ve testerlerin birbirlerine genetik olarak yakınlıkları ve uzaklıkları dendogram olarak çıkartılmıştır (Şekil 1). Çalışmamızda hat olarak kullanılan R4062 ve R4046 nolu hatların genetik olarak birbirlerine çok yakın oldukları dikkati çekmektedir. Bu hatların resiprokal melezleri ise bazı özellikler bakımından farklı oldukları da dikkati çekmektedir. Her ne kadar hücre çekirdek genlerine dayalı olarak benzerlikleri yüksek olsa da, bu ebeveynlerin sitoplazma genleri bakımından farklılık 
gösterdiği anlaşılmaktadır. Bu nedenle de resiprokal melezleme ile oluşturulan hatlarda verim, bitki boyu, parselde koçan sayısı ve koçan bağlama yüksekliği özelliklerine ait GKG değerlerinin farklılık gösterdiği görülmektedir.

Testerler içerisinde FR697 ile GS3515'in birbirlerine benzerlikleri GS3507 testerinden daha yüksek orandadır (Şekil 1). Buna karşın çalışmada ele aldığımız özellikler bakımından FR697'nin parselde koçan sayısı özelliği dışındaki diğer özellikleri bakımından farklı GKG değerlerine sahip olduğu görülmektedir. Bu durum bu iki tester arasındaki genotipik benzerliğin çalışmada ele alınan özelliklerin dışındaki genler bakımından bir benzerliğin bulunduğunu göstermektedir.

\section{Sonuç}

Dört hat ve üç testerin çoklu dizi analizine göre melezlenerek elde edilen 12 melez kombinasyonun tane verimi ve bazı verim komponentlerinin incelenmesi sonucunda; özellikle tane veriminde, bitki boyunda, koçan bağlama yüksekliğinde, koçanda sıra sayısında ve sırada tane sayısı özelliklerinde gerek hatlar gerekse testerler ve melez kombinasyonlar arasında istatistiksel olarak önemli farklılıkların bulunduğu dikkati çekmektedir. Bu farklılıklara dayalı olarak oluşturulan melez populasyonlardan ıslah amacına uygun melez kombinasyonların seçilme olanağı bulunmaktadır. Bunun yanında denemede ele alınan özellikler bakımından bazı hat ve testerlerin bu özelliklerin geliştirilmesinde ebeveyn olarak kullanılabileceklerini göstermektedir.

Tane verimi özelliği bakımından hatlardan (R4062 x R4046) ebeveyninin genel kombinasyon gücü değerine dayalı olarak melez kombinasyonlarda tane verimini arttırmak için uygun bir ebeveyn olabileceği anlaşılmaktadır. Ayrıca özel kombinasyon gücü değerleri dikkate alınarak R4062 x FR697 ve R4046 x GS3507 melez kombinasyonlarının tane verimi açısından ümitvar kombinasyonlar oldukları söylenebilir.

Çalışmamız sonucunda incelenen tüm karakterler birlikte değerlendirildiğinde R4062xR4046 hattının verim, koçanda sıra sayısı, sırada tane sayısı özelliklerini döllerine yüksek oranda aktarabilme yeteneğine sahip olduğu ve bu amaçla ıslah çalışmalarında kullanılabileceği anlaşılmaktadır. Aynı zamanda bu R4062 ve R4046 hatlarının çekirdek genlerinin büyük ölçüde birbirine benzediği de moleküler analizlerle ortaya konmuştur. Testerler içerisinde ise koçan bağlama yüksekliği, koçanda sıra sayısı ve sırada tane sayısı özellikleri bakımından FR697'nin ıslah çalışmalarında iyi bir tester olarak kullanılabileceği görülmektedir. FR697'nin moleküler analizler sonucunda GS3515 ile daha yakından bir benzerliği olmasına karşın, diğer tester olan GS3507 ile genetik benzerlik bakımından daha uzak olduğu saptanmıştır. Melezler içerisinde ise R4062xFR697 tek melezinin tane verimi açısından, R4046xGS3507 melez kombinasyonunun ise tane verimi, koçan bağlama yüksekliği ve sırada tane sayısı açısından ümitvar hibrit kombinasyonları oluşturdukları ve dendogram analizlerinde de bu genotiplerin birbirlerinden genetiksel olarak uzak akraba oldukları dikkati çekmektedir. Bu kombinasyonların diğer agronomik ve kalite özellikleri de incelenerek hibrit çeşit olarak ele alınabilecekleri sonucuna varılmıştır.

\section{Kaynaklar}

Bozbek T., 2006. Pamuk Melez Populasyonlarında Verim Bileşenlerinin Kalıtımı ve Genetik Korelasyonların Saptanması (Doktora Tezi). Adnan Menderes Üni. Fen Bilimleri Enst., Tarla Bitkileri Anabilim Dalı, 116p

Cengiz R., 2011. Mısır Hatları Arasındaki 8x8 Yarım Diallel M Elez Döllerinde Verim ve Verim Unsurlarının Kalıtımları Üzerine Araştırmalar (Yüksek Lisans Tezi). Trakya Üni. Fen Bilimleri Enstitüsü, $160 \mathrm{~s}$

Davis R.L., 1927. Report of the Plant Breeder. Report of the Puerto Rico Agriculture Experiment Station, Puerto Rico, pp.14-15

Falconer D.S., 1981. Introduction to Quantitative Genetics. Donald Press Co., New York, USA

Griffing J.B., 1956. A generalized treatment of the use of diallel crosses in quantitative inheritance. Heredity, 10: 31-50

Hayman B.I., 1954. The Theory And Analysis of Diallel Crosses. Genetics, 39: 789-809

Kempthorne O., 1957. An introduction to genetic statistics. John Wiley and Sons. Inc., New York

Mathur R.K. and Bhatnagar S.K., 1995, Partial diallel cross analysis for grain yield and its component characters in maize. Annals of Agricultural Research, 16(3): 324-329

Özcan S., 2009. Modern dünyanın vazgeçilmez bitkisi mısır: genetiği değiştirilmiş (transgenik) mısırın tarımsal üretime katkıSı. Türk Bilimsel Derlemeler Dergisi, 2(2), 01-34 